\title{
Study of inflammatory markers and autonomic functions in development of cardiovascular disease and Diabetes Mellitus in a student population.
}

\author{
Karandikar MS ${ }^{1}$, Prasad NB ${ }^{2}$, Priyam Choudhury ${ }^{3}$ \\ ${ }^{1}$ Professor,Department of Physiology, Dr. D. Y. Patil Medical College and Research Center, \\ Dr. D Y Patil Vidyapeeth.Pune. \\ ${ }^{2}$ Associate Professor, Department of Physiology, Dr. D. Y. Patil Medical College and Research Center, \\ Dr. D Y Patil Vidyapeeth.Pune. \\ ${ }^{3}$ MBBS student, Dr. D. Y. Patil Medical College and Research Center, Dr. D Y Patil Vidyapeeth.Pune.
}

\begin{abstract}
Background-Elevated inflammatory markers such as high sensitivity $C$-reactive protein (hs-CRP), TNF-alpha, IL-6,serum amyloid A and leukocyte count are associated with future risk of development of type 2 diabetes and cardiovascular disease. Similarly Cardiac Autonomic Neuropathy (CAN) is also an early indicator of cardiovagal dysfunction.

Objective- Obesity is an inflammatory condition. A study was conducted to evaluate the role of inflammatory markers and autonomic function in development of cardiovascular disease and Diabetes Mellitus in an obese population.

Methods and Results- The study was conducted on 30 obese male students and 30 non obese male in the age range of 18-24 years, from $\operatorname{Dr} D$. Y. Patil University, Pune. Leukocyte count, C-reactive protein (CRP) and cardiac autonomic function tests were carried out in all subjects. Results showed significant decrease in heart rate variability $(H R V)$ in obese subjects. However, no significant difference was seen in the levels of CRP and leukocyte count in between obese and non obese subjects.

Conclusion-The study showed early signs of autonomic imbalance in the obese subjects, but inflammation does not seem to play a role in this age group in the present set up.
\end{abstract}

Key words: Obesity, C-reactive protein, Leukocyte count, Cardiac Autonomic Neuropathy

Submitted Date 05 July 2013

Accepted Date: 10 July 2013

\section{Introduction}

Recent evidence indicates that obesity is an inflammatory condition [1]. It has been proposed that inflammatory cytokines secreted by adipose tissue exert an endocrine effect conferring insulin resistance in liver, skeletal muscle and vascular endothelial tissue ultimately leading to the clinical expression of both type 2 diabetes and cardiovascular disease(CVD)[2,3].Half of all myocardial infarctions occur in persons in whom plasma lipid levels are normal.[4] With the recognition that atherosclerosis is an inflammatory process[5] ,several plasma markers of inflammation have been evaluated as potential tools for prediction of the risk of coronary events .Among them are markers of systemic inflammation produced in the liver, such as high sensitivity C- reactive protein(hs-CRP) and serum amyloid A; cytokines such as interleukin-6;and adhesion molecules such as soluble intercellular adhesion molecule type 1.[6-13].The results of large prospective studies suggest that inflammation may be an underlying pathophysiological mechanism of several of the adverse clinical outcomes associated with obesity and insulin resistance. For example, increased levels of inflammatory markers, such as leukocyte count and CRP, are associated with the future development of type 2 diabetes, cardiovascular disease, and death [14-22]. Of the 12 plasma measures of inflammatory makers evaluated in the Womens Health Study,hs-CRP was found to be the most significant predictor of the risk of cardiovascular events[22].It has also been found that hs-CRP level remains stable over long periods provided there is no acute infection within two to three weeks[23,24].

Cardiac autonomic neuropathy (CAN) is a major complication as it carries a five-fold risk of mortality in patients with diabetes and is usually related to myocardial infarction \& cardiac arrhythmias. Typical findings referring to autonomic dysfunction may include exercise intolerance, orthostatic hypotension and cardiac dysfunction at rest or exercise. Heart rate variability (HRV), defined as degree of fluctuation of the beat-to-beat differences in cardiac rhythm, is known to be a reliable, noninvasive marker of autonomic nervous system activity $[25,26]$.Loss of heart rate variability is an indication of cardiovascular disease and can reliably predict poor outcome of such conditions [27-30]

We conducted this study to evaluate the role of inflammatory markers and autonomic functions in obese young individuals aged between 18-24 years. This would help us to ascertain the exact role of the 
inflammatory process and autonomic dysfunction in the early onset of both cardiovascular disease \& diabetes mellitus in young obese subjects.

\section{Methods}

A total of 60 male students in the age range of 18-24 years, from Dr.D. Y.Patil University,Pune were selected for the present study. Their Anthropometric measurements (height and weight) were taken by using scales on bare foot and their Body mass index (BMI) and Waist Hip Ratio (WHR) were calculated. Thirty students who had BMI $>25$ and WHR $>0.9[31]$ were categorized as obese. 30 students with BMI $<25$ and WHR $<0.9$ formed the controls. Blood chemistry of these sixty students was studied for glucose (glucose oxidase method) and lipid levels(enzymatic end point method) [32].Hematological investigations like Total Leukocyte Count (TLC) and Differential Leukocyte Count (DLC) were carried out (hemocytometry method).Qualitative measure of CRP was carried out by using CRP Latex Reagent kit[33]. Resting heart rate, Systolic and Diastolic blood pressures were also measured.

Autonomic function tests [34] were performed as follows on each student in an environment with room temperature ranging from $23^{\circ} \mathrm{C}$ to $25^{\circ} \mathrm{C}$ using computerized polyrite-D (ModalDSMP0410,RMS,Chandigarh,India).

\section{Heart-rate response to Valsalva manoeuvre(Valsalva ratio)}

The test was performed by the subject (student) blowing into a mouthpiece connected to a modified sphygmomanometer and holding it at a pressure of $40 \mathrm{~mm} \mathrm{Hg}$ for 15 seconds while a continuous electrocardiogram was recorded. The manoeuvre was performed three times with one minute intervals between. The result was expressed as the Valsalva ratio, which is the ratio of the longest R-R interval after the manoeuvre (reflecting the overshoot bradycardia following release) to the shortest R-R interval during the manoeuvre (reflecting the tachycardia during strain). The highest of the three Valsalva ratios(VR) was taken as the final value. Subjects with autonomic dysfunction may have decreased values of VR.

\section{Heart-rate variation during deep breathing(Deep Breath Difference)}

The subject sits quietly and breathes deeply at six breaths a minute (five seconds in and five seconds out) for one minute. An electrocardiogram was recorded throughout the period of deep breathing, with a marker used to indicate the onset of each inspiration and expiration. The result is then expressed as the mean of the difference between maximum and minimum heart rates for the six measured cycles.Subjects with autonomic neuropathy may have a noticeable reduction in, and sometimes complete absence of, heart-rate variation.

\section{Immediate heart-rate response to standing(30:15 RR ratio)}

The test is performed with the subject lying quietly on a couch while the heart rate is recorded continuously on an electrocardiograph. The patient is then asked to stand up unaided, and the point at starting to stand is marked on the electrocardiogram. The characteristic heart rate response is expressed by the 30:15 RR ratio. It is the ratio of shortest R-R interval at or around the 15 th beat and the longest $\mathrm{R}-\mathrm{R}$ interval at around the 30th beat after starting to stand. Subjects with autonomic neuropathy may have a noticeable reduction in the ratio.

\section{Blood-pressure response to standing or Orthostatic tolerance test(OTT)}

The test is performed by measuring the patient's blood pressure with a sphygmomanometer while he is lying down quietly and again when he stands up. The postural fall in blood pressure is taken as the difference between the systolic blood pressure lying and the systolic blood pressure standing. In subjects with autonomic damage or dysfunction the blood pressure falls on standing and remains lower than in the lying position.

The study was approved by institutional ethics committee. Computations were performed using SigmaStat statistical package (Jandel Scientific, version 4 for Windows, SPSS Inc., Chicago, USA).Results were expressed as mean +/-SEM for normally distributed variables or as median and interquartile range when data was not normally distributed. Difference between groups was tested by Student's t-test, Mann Whitney test or Chi-square as appropriate.

\section{Results}

In the present study 30 obese subjects of age range between 18-24 years were compared with 30 non obese subjects of same age group and sex. The Parameters studied are shown in Table $1 \& 2$.

The fasting and the post- prandial blood glucose levels were elevated in the obese group but were not statistically significant .Total cholesterol was statistically significantly $(\mathrm{p}=0.0001)$ higher in obese subjects.Triglyceride, LDL and blood sugar levels were also high in obese subjects but were not significant. Similarly, TLC and DLC were also high in obese subjects, but results were not statistically significant. CRP was 
negative in both the groups. Resting pulse was higher in the obese group as compared to the nonobese. $(\mathrm{p}=0.0054)$.Valsalva ratio $(\mathrm{p}=0.0047)$ and deep breath difference $(\mathrm{p}=0.01)$ were statistically significantly low in obese subjects, systolic blood pressure $(\mathrm{p}=0.0013)$ and $\mathrm{OTT}(\mathrm{p}=0.0001)$ values were statistically significantly high in obese subjects. However 30:15 RR ratio \& diastolic pressure showed no difference.

\section{Discussion}

Obesity is a known inflammatory condition in which the inflammatory cytokines secreted by adipose tissue exert an endocrine effect conferring insulin resistance ultimately leading to type 2 Diabetes Mellitus and Cardiovascular Disease. Elevated levels of adipocyte cytokines ,such as tumor necrosis factor-alpha and interleukin-6, leads to an acute-phase response with increased production of high sensitive C-Reactive protein which is a sensitive marker for systemic inflammation. CRP has the strongest positive association with type 2 Diabetes Mellitus and Cardiovascular Disease than any other inflammatory marker. In the Insulin Resistance Atherosclerosis Study and the MONICA Augsburg Cohort Study, the association of CRP with diabetes disappeared after adjustment for BMI[35].In the Mexico City Diabetes study,CRP was an independent predictor of metabolic syndrome and type 2 Diabetes Mellitus in women but not in men[36]. When studied in a large sample size it has been found that CRP has a stronger and independent association with diabetes. Elevated CRP also releases E-selectin,ICAM-1, VCAM-1 and other mediators of impaired vascular reactivity.[37], thus high level of CRP also marks endothelial dysfunction and subclinical atherosclerosis.As suggested by Framingham Heart Study there was a direct correlation between CRP and CAC( Coronary artery calcification) in both men and women.Of all the inflammatory markers, hs-CRP was the most significant predictor of the risk of Cardiovascular Disease[6] .

In this study,Total Cholesterol (TC) level was found to be significantly higher in the obese group $(\mathrm{p}=$ 0.0001). Triglyceride levels were higher in the obese group but were not significant. As urbanization occurs, increase in BMI, dietary changes and reduced physical activities result in an elevation of TC. Similar results were found in other studies[3]. There was however no significant difference in HDL-C, \& LDL-C between the two groups.This study found only increased levels of total cholesterol.The artherogenic dyslipidaemia with increased LDL and decreased HDL levels which are frequently considered to be a coronary risk factor for the Indian population was absent in this study. This is at variance with the lipid profile seen in adult Indians. This may be due to the smaller sample size used in this study. Another possible reason could be that plasma lipids varies significantly in various population groups due to geographical, cultural, economical, social conditions, dietary habits and finally the genetic makeup. However this would require further evaluation.

The CRP was negative in both the obese and non obese groups.Total Leukocyte count was higher in the obese group but was non-significant.The differential count (DLC) showed no difference between the two groups. Thus the obese group shows no indication of a clinical or sub-clinical inflammatory process that may have set in. Whether this was due to the smaller sample size or whether the changes are not yet seen in this young age group requires further validation. Most of the studies on the inflammatory markers have been carried out in an age group above 40 years. To confirm these observations, would require a follow up study of this group with additional inflammatory markers, if required, to completely delineate the role of inflammatory markers in the etiology of cardiovascular disease \& Diabetes Mellitus in this age group.

The pulse rate was significantly higher in the obese group $(\mathrm{p}=0.0054)$ as compared to the control group indicative of vagal dysfunction. The present study found a significant decrease in the Valsalva Ratio $(0.0047)$ and Deep Breath Difference (0.01) but no significant change in 30:15 RR ratio. Systolic blood pressures were higher in the obese groups $(\mathrm{p}=0.0013)$ and with Orthostatic tolerance test (OTT),fall in systolic blood pressure was found to be significantly higher in the obese group $(\mathrm{p}=0.00013)$. This could be indicative of early autonomic dysfunction in these obese students. The Heart rate variability (HRV) analysis especially at respiratory frequencies provides information about cardiac vagal efferent activity of the autonomic nervous system. Morbidly obese individuals have increased HR and low HRV, indicating an abnormal cardiac autonomic function. An analysis of HRV at respiratory frequencies is the most sensitive method for the diagnosis of cardiovagal dysfunction in obesity.Some studies have found lower respiratory sinus arrhythmia, that indicates a cardio-vagal dysfunction in obese adolescents and provides important diagnostic information about early subclinical autonomic dysfunction in obesity [38].

The fasting and the post- prandial blood glucose levels were elevated in the obese group but were not statistically significant.A meta-analysis including 95,783 subjects followed on average for 12.4 years demonstrated an exponential relationship between the incidence of cardiovascular events and 2 hour post prandial plasma glucose. Several other studies including Hoorn Study, Honolulu Heart Study and the Chicago Heart Study have shown that the glucose level two hours after an oral glucose challenge is a powerful predictor of cardiovascular risk.[39]. 
The present study has thus shown that the obese group probably shows early signs of autonomic imbalance, though the inflammatory process has not yet set in this group. This early detection of autonomic imbalance should help in planning for suitable remedial measures to minimize or possibly correct the imbalance at an early age.

\section{Conclusions.}

It can be inferred that although inflammatory process has not yet set in,autonomic and cardio-vagal dysfunction can be seen in the obese group at an early age with no overt signs of diabetes \& cardiovascular disease.

\section{Acknowledgements}

The above work was an ICMR-STS (Indian council of medical research- short term studentship) funded project.The authors wish to express their gratitude to Drs. Anindyo Roy \& Arunima Chaudhary for their help.

\section{References}

[1]. Das UN,Is obesity an inflammatory condition?, Nutrition ,17,2001,953-966.

[2]. Yudkin JS, Stehouwer CD, Emeis JJ, Coppack SW, C-reactive protein in healthy subjects: associations with obesity, insulin resistance, and endothelial dysfunction: a potential role for cytokines originating from adipose tissue? ,Arterioscler Thromb Vasc Biol 19,1999,972-978

[3]. Hu FB, Stampfer MJ, Is type 2 diabetes mellitus a vascular condition?, Arterioscler Thromb Vasc Biol 23, 2003,1715-1716,

[4]. Braunwald E. Shattuck Lecture - cardiovascular medicine at the turn of the millennium: triumphs, concerns, and opportunities. N Engl J Med,337,1997,1360-9.

[5]. Ross R. Atherosclerosis - an inflammatory disease. N Engl J Med .340,1999,115-26.

[6]. Pual MR,Charles H H,Julie EB, Nader R ,C-reactive protein and other markers of inflammation in the prediction of cardiovascular disease in women. N Engl J Med ,342(12),2000,836-843

[7]. Kuller LH, Tracy R P, Shaten J, Meilahn EN. Relationship of C-r eactive protein and coronary heart disease in the MRFIT nested case-control study: Multiple Risk Factor Intervention Trial. Am J Epidemiol ,144,1996,537-47.

[8]. Tracy RP, Lemaitre RN, Psaty BM, et al. Relationship of C-reactive protein to risk of cardiovascular disease in the elderly: results from the Cardiovascular Health Study and the Rural Health Promotion Project. Arterioscler Thromb Vasc Biol 17,1997,1121-7.

[9]. Ridker PM, Cushman M, Stampfer MJ, Tracy RP, Hennekens CH. Inflammation, aspirin, and the risk of cardiovascular disease in apparently healthy men. N Engl J Med 336,1997,973-9.

[10]. Koenig W, Sund M, Frohlich M, et al. C-reactive protein, a sensitive marker of inflammation, predicts future risk of coronary heart disease in initially healthy middle-aged men: results from the MONICA (Monitoring Trends and Determinants in Cardiovascular Disease) Augsberg Cohort Study, 1984 to 1992. Circulation99,1999,237-42.

[11]. Harris TB, Ferrucci L, Tracy RP, et al. Associations of elevated interleukin- 6 and C-reactive protein levels with mortality in the elderly. Am J Med106,1999,506-12.

[12]. Ridker PM, Hennekens CH, Roitman-Johnson B, Stampfer MJ, Allen J. Plasma concentration of soluble intercellular adhesion molecule 1 and risks of future myocardial infarction in apparently healthy men. Lancet ,351,1998,351:88-92.

[13]. Hwang S-J, Ballantyne CM, Sharrett AR, et al. Circulating adhesion molecules VCAM-1, ICAM-1, and E-selectin in carotid atherosclerosis and incident coronary heart disease cases: the Atherosclerosis Risk In Communities (ARIC) study.Circulation 96,1997,4219-25.

[14]. Wolf M, Sauk J, Shah A, Vossen Smirnakis K, Jimenez-Kimble R, Ecker JL, Thadhani R. Inflammation and glucose intolerance: a prospective study of gestational diabetes mellitus, Diabetes Care.Jan;27(1), 2004 21-7.

[15]. Festa A, D’Agostino R Jr, Howard G, Mykkanen L, Tracy RP, Haffner SM: Chronic subclinical inflammation as part of the insulin resistance syndrome: the Insulin Resistance,Atherosclerosis Study (IRAS). Circulation 102,2000,42-47.

[16]. Vozarova B, Weyer C, Lindsay RS, Pratley RE, Bogardus C, Tataranni PA: High white blood cell count is associated with a worsening of insulin sensitivity and predicts the development of type 2 diabetes, Diabetes 51,2002,455-461.

[17]. Weyer C, Yudkin JS, Stehouwer CD, Schalkwijk CG, Pratley RE, Tataranni PA: Humoral markers of inflammation and endothelial dysfunction in relation to adiposity and in vivo insulin action in Pima Indians. Atherosclerosis 161,2002,233-242.

[18]. Tamakoshi K, Yatsuya H, Kondo T, Hori Y, Ishikawa M, Zhang H, Murata C, Otsuka R, Zhu S, Toyoshima H: The metabolic syndrome is associated with elevated circulating C-reactive protein in healthy reference range, a systemic low-grade inflammatory state. Int J Obes Relat Metab Disord 27,2003,443-449.

[19]. Frohlich M, Imhof A, Berg G, Hutchinson WL, Pepys MB, Boeing H, Muche R, Brenner H, Koenig W: Association between Creactive protein and features of the metabolic syndrome: a population-based study. Diabetes Care 23,2000,1835-1839.

[20]. Pickup JC, Mattock MB, Chusney GD, Burt D: NIDDM as a disease of the innate immune system: association of acutephase reactants and interleukin-6 with metabolic syndrome X. Diabetologia,1997, 40: 1286-1292.

[21]. Pradhan AD, Cook NR, Buring JE, Manson JE, Ridker PM: C-reactive protein is independently associated with fasting insulin in nondiabetic women. Arterioscler Thromb Vasc Biol 23,2003,650-655.

[22]. Ridker PM, Hennekens CH, Buring JE, Rifai N: C-reactive protein and other markers of inflammation in the prediction of cardiovascular disease in women. N Engl J Med 342,2000:836-843.

[23]. Ridker PM, Rifai N, Pfeffer MA, Sacks F, Braunwald E. Long-term effects of pravastatin on plasma concentration of C-reactive protein. Circulation 100,1999,230-5.

[24]. Macy EM, Hayes TE, Tracy RP. Variability in the measurement of C-reactive protein in healthy subjects: implications for reference intervals and epidemiologic applications. Clin Chem 43,1997:52-8.

[25]. Malik M, Camm AJ. Heart rate variability. Clin Cardiol 1990;13: 570-576.

[26]. Kamath MV, Fallen EL. Power spectral analysis of heart rate variability: a noninvasive signature of cardiac autonomic function. Crit Rev Biomed Eng 1993;21:245-311.

[27]. Francis J, Weiss RM, Wei SG, Johnson AK, and Felder RB. Progression of heart failure after myocardial infarction in the rat. Am J Physiol Regul Integr Comp Physiol 281,2001, R1734-R1745. 
[28]. Grippo AJ, Moffitt JA, and Johnson AK. Cardiovascular alterations and autonomic imbalance in an experimental model of depression. Am J Physiol Regul Integr Comp Physiol 282,2002,R1333-R1341.

[29]. Lanfranchi PA and Somers VK. Arterial baroreflex function and cardiovascular variability: interactions and implications.Am $J$ Physiol Regul Integr Comp Physiol 283,2002, R815-R826.

[30]. Task Force of the European Society of Cardiology and the North American Society of Pacing and Electrophysiology Circulation. Heart rate variability: standards of measurement,physiological interpretation, and clinical use. Circulation 93,1996,1043-1065.

[31]. WHO/IASO/IOTF:The Asia-Pacific Perspective:Redifining obesity \& its treatment.Melbourne Health Communications, Australia:2000.

[32]. Teitz, N.W. Fundamentals of Clinical Chemistry (4 ed), W.B. Saunders \& Co. Philidelphia PA 1996.

[33]. Andersen HC, McCarthy M,Am.J.Med,8,445.1950

[34]. EWING DJ,CLARKE BF.Diagnosis and management of diabetic autonomic Neuropathy. British Medical Journal Volume 285(2) October 1982.Pp 916-918

[35]. Festa A,Tracy RP, Haffner SM: Elevated levels of acute phase proteins and plasminogen activator inhibitor-1 predict the development of type 2 -Diabetes:The insulin resistance atherosclerosis study.DIABETES 51,2002,1131-1137.

[36]. Hans TN, Sattar N, Williams K et al :Prospective study of C-Reactive Protein in relation to the development of diabetes and metabolic syndrome in the Mexico City Diabetes Study, DIABETES CARE :25,2002,2016-2021..

[37]. Gabay C, Kushner I:Acute phase proteins an other systemic responses to inflammation N ENG J MED 340,1999,448-454.

[38]. Tonhajzerova I, Javorka M, Trunkvalterova Z, Chroma O, Javorkova J, Lazarova Z, Ciljakova M, Javorka K .Cardio-respiratory interaction and autonomic dysfunction in obesityJ Physiol Pharmacol. 2008 Dec;59 Suppl 6:709-18

[39]. Coutinho M, Gerstein HC et el.The relationship between glucose and cardiovascular events.Diabetic Care1999;22:B $21-$ B 9 .

Table.1:Anthropometry \& Biochemical Profile

\begin{tabular}{|l|l|l|l|}
\hline PARAMETERS & $\begin{array}{l}\text { NON- OBESE } \\
\text { N=30 }\end{array}$ & $\begin{array}{l}\text { OBESE } \\
\text { N=30 }\end{array}$ & p-VALUES \\
\hline Waist Hip Ratio & 0.82 & 0.90 & $0.0014^{*}$ \\
\hline BSL-Fasting(Mg/dl) & 79.5 & 82 & 0.0948 \\
\hline BSL-Post Prandial(Mg/dl) & 114.9 & 115.8 & 0.6767 \\
\hline Total Cholesterol(Mg/dl) & $119.4 \pm 2.44$ & $154.2 \pm 3.58$ & $0.0001^{*}$ \\
\hline Triglyceride(Mg/dl) & 102 & 107.5 & 0.0977 \\
\hline HDL(Mg/dl) & 45.6 & 45 & 0.6958 \\
\hline LDL(Mg/dl) & 68 & 69 & 0.4508 \\
\hline TLC (Per c.mm.) & $7206.7 \pm 148.6$ & $7656.7 \pm 191.8$ & 0.0687 \\
\hline Neutrophils $(\%)$ & 63 & 62.5 & 0.9352 \\
\hline Lymphocyte(\%) $(\%)$ & 32 & 0.1241 \\
\hline Monocytes(\%) & 34.5 & 2 & 0.8186 \\
\hline Eosinophil(\%) & 2 & 1 & 0.3906 \\
\hline CRP & 1 & Negative & \\
\hline
\end{tabular}

Table 2: Autonomic Function Tests

\begin{tabular}{|l|l|l|l|}
\hline PARAMETERS & $\begin{array}{l}\text { NON- OBESE } \\
\mathrm{N}=30\end{array}$ & $\begin{array}{l}\text { OBESE } \\
\mathrm{N}=30\end{array}$ & p-VALUES \\
\hline Pulse(Beats/Min) & $72.1 \pm 1.01$ & $76.9 \pm 1.34$ & $0.0054^{*}$ \\
\hline Valsalva Ratio & 1.44 & 1.37 & $0.007^{*}$ \\
\hline Deep Breath Difference & 33.5 & 29.6 & $0.0100^{*}$ \\
\hline 30:15 RR Interval & 1.03 & 1.03 & 0.5843 \\
\hline Systolic pressure(mm Of Hg) & $123.6 \pm 0.927$ & $128.5 \pm 1.122$ & $0.0013^{*}$ \\
\hline Diastolic pressure(mm Of Hg) & $81.8 \pm 1.11$ & $80.1 \pm 1.06$ & 0.6352 \\
\hline OTT(mm Of Hg) & 1.3 & 1.8 & $0.0001^{*}$ \\
\hline
\end{tabular}

Results are expressed as mean +/-SEM for normally distributed variables or as median and interquartile range when data was not normally distributed. Difference between groups was tested by Student's t-test, Mann Whitney test or Chi-square as appropriate.

*Indicates significance 